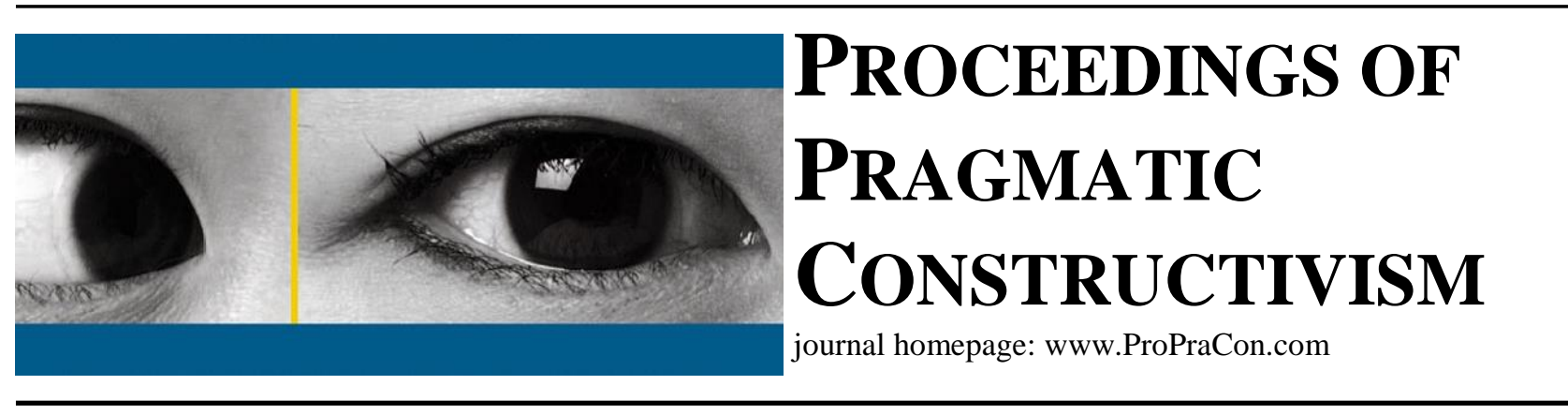

\title{
Digit accounting as language game for managing organizational spaces
}

\author{
Daniela Ruggeri \\ University of Catania, UNICT · Department of Economics and Business \\ E-mail: d.ruggeri@unict.it \\ Antonio Leotta \\ University of Catania, UNICT · Department of Economics and Business \\ E-mail: antonio.leotta@unict.it \\ Carmela Rizza \\ University of Catania, UNICT · Department of Economics and Business \\ E-mail: c.rizza@unict.it
}

\begin{abstract}
The growth of an organization, increasing its complexity, has often entailed the needs to reconfigure the space where organizational practices are accomplished. The relation between accounting and spatial practices has been highlighted by Carmona et al. (2002) pointing out how the reconfiguration of new spatial practices based on a more specialized division of labour has entailed an increase in the discipline of control both in the form of a direct control, associating each single space unit to a person and vice versa, and in the form of accounting control, increasing the frequency of various accounting practices. If, on the one hand, the reconfiguration of the organizational space entails an increased use of accounting control practices, on the other hand, the increased use of accounting defines new organizational spaces. As the authors argue: “...accounting can produce intricate coding systems by attaching quantities and values to individuals, activities and spaces. Coding through accounting makes possible the creation of an analytical and useful space; an accounting space articulated upon physical factory space that makes possible the assessment, comparison, ranking and differentiation of operators and activities” (cfr: p. 244). The technical and social specificities that characterize each organizational space as a specific community have to interact with the whole organization as a unitary space for value creation. This is expressed through the concept of organization as a polyphony (Backin, 1984; Kornberger et al., 2006), which makes sense of the existence of multiple languages associated with the various organizational spaces which, at the same time, have to converge toward only one language, that of the whole organization.

The accounting phenomenon is engaged in mediating among specific organizational spaces in order to promote the visibility of the whole organization as a unitary space for value creation. Studying accounting to this aim gives the chance to address the research perspective arisen by Carmona et al. (2002), namely: "addressing more explicitly issues of employee resistance in their 'everyday life' (Lefebvre, 1991) in dealing with imposed routinized spatial and accounting practices” (cfr: 273). In trying to address this issue we extend it by considering the potentials of accounting in the current digitalized society.

Considering digit accounting and its reporting capabilities leads to the study of accounting as principles and rules for communication, namely as a language. The functioning of accounting needs the sharing by its users of the same rules and principles that lead to the same meanings: this occurs in a specific context. We thus refer to the concept of language game conceptualized by Wittgenstein (1953) to study how digit accounting shapes the relation with the organizational spaces. Given that any language game refers to a specific context, digit accounting language game needs to be related to a specific organizational space. At the same time, the use of organizational space as a means of accounting control by the whole organization needs the use of digit accounting as a language game with respect to the
\end{abstract}


whole organizational context. The specific accounting language game needs to be combined with the accounting language game of the whole organization. The related question is: does digit accounting favour the combination between accounting language games arising from different organizational spaces?

To address this question we examined the case of the control of new product development processes in a multidivisional and multinational company operating in the semiconductor industry. The choice of this case is due to the multidivisional and multinational nature of the company that appropriately represents the local, specific organizational spaces through the company divisions, which differ in their products and process technologies. Furthermore, the case is chosen as it offers evidence on the control of NPD process, whose role is still ambiguous in the extant literature. Particularly, the case refers to a digit accounting system development and implementation, which is at its validation stage. The findings reveal further aspects that are relevant other than the unitary language of the corporate and the divisions, such as that the meaning of the digit accounting outputs should be consistent in their different uses, namely in NPD processes, in managers' performance evaluation, in strategic decision making. In all, the willingness of divisional managers to accept and use the output of digit accounting system depends on how the corporate managers believe in the meaning of those outputs. 